\title{
Density-dependent demography and movements in a cyclic brown lemming population
}

\author{
Dominique Fauteux ${ }^{1}$ and Gilles Gauthier ${ }^{2}$ \\ ${ }^{1}$ Canadian Museum of Nature \\ ${ }^{2}$ Centre d'études nordiques
}

January 19, 2022

\begin{abstract}
Theoretical modelling predicts that both direct and delayed density-dependence are key factors to generate population cycles. Deciphering density-dependent processes that lead to variable population growth characterizing different phases of the cycles remain challenging. This is particularly the case for the period of prolonged low densities, which is inherently data deficient. However, demographic analyses based on long-term capture-mark-recapture datasets can help resolve this question. We relied on a 16-yr (2004-2019) live-trapping program to analyse the summer demography and movements of a cyclic brown lemming population in the Canadian Arctic. More specifically, we examined if inversely density-dependent processes could explain why population growth can remain low during the prolonged low phase. We found that the proportion of females in the population was inversely density-dependent with a strong male-biased sex ratio at low densities but not at high densities. However, survival of adult females was higher than adult males, but both had lower survival at low densities than at high ones. Distances moved by both adult males and females were density-dependent, and proportion of females in reproductive condition was weakly density-dependent as it tended to increase at low density. Individual body condition, measured as monthly change in body mass, was not density-dependent. Overall, the strong male-biased sex ratio at very low densities suggests a loss of reproductive potential due to the rarity of females and appears to be the most susceptible demographic factor that could contribute to the prolonged low phase in cyclic brown lemmings. What leads to this sex-bias in the first place is still unclear, potentially owing to our trapping period limited to the summer, but we suggest that it could be due to high predations rate on breeding females in winter.
\end{abstract}

\section{Hosted file}

Fauteuxetal_DDlemmings_maintext_PLAIN.pdf available at https://authorea.com/users/393018/ articles/553274-density-dependent-demography-and-movements-in-a-cyclic-brown-lemmingpopulation 